\title{
PRETERM LABOUR
}

\author{
Geoffrey Chamberlain
}

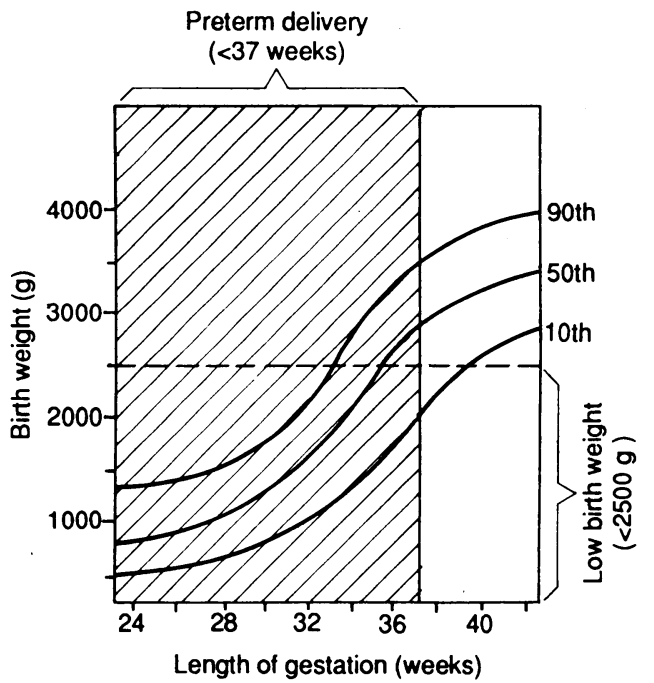

Preterm labour may result in the birth of an immature infant. Together with intrauterine growth retardation it is the main problem of obstetric care in the United Kingdom in the 1990s. The conventional definition of preterm labour includes women delivering before 37 completed weeks of gestation, but in practice in the United Kingdom problems arise mostly with births before 34 weeks. Babies more mature than this can be cared for successfully in many district general hospitals without intensive care facilities; many problems can arise in looking after babies weighing less than $1500 \mathrm{~g}$ (3.5 lbs).

Relation between length of gestation and birth weight. Babies born in the crosshatched area are preterm irrespective of weight.

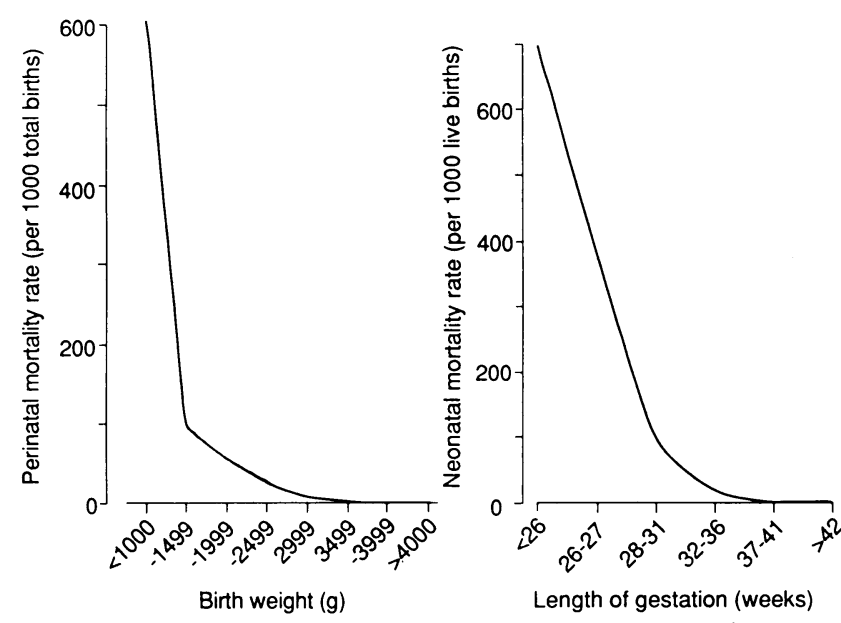

Perinatal mortality rates relate sharply to maturity and birth weight; similarly, neonatal mortality rates relate to gestational age at birth. Probably some $6 \%$ of babies in the United Kingdom are born before 37 weeks and 2\% before the 32nd week of pregnancy.

Birthweight specific perinatal mortality rates and gestation specific neonatal mortality rates for Scotland in 1988.

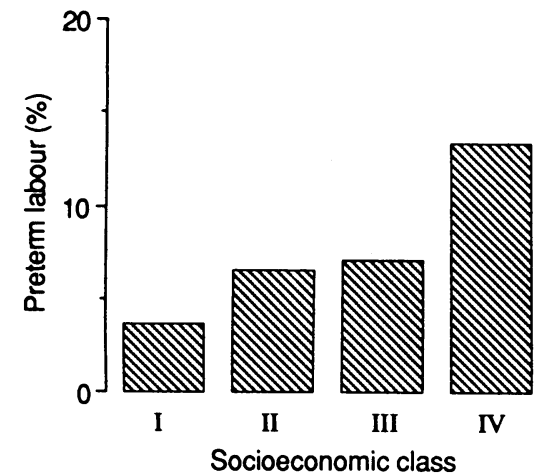

Relation between socioeconomic class and preterm labour among 12000 pregnancies assessed prospectively.

\section{Causes}

Sociobiological background-The capa..., . . preterm labour is often predictable by a clustering of high risk factors. The mother's age, parity, and socioeconomic class bear strong associations with preterm labour. Socioeconomic class is an indicator of the woman's behaviour, nutrition, smoking, and previous medical and social existence. They may not be individual factors in their own right but are useful to designate women whose risk of preterm labour is increased. 


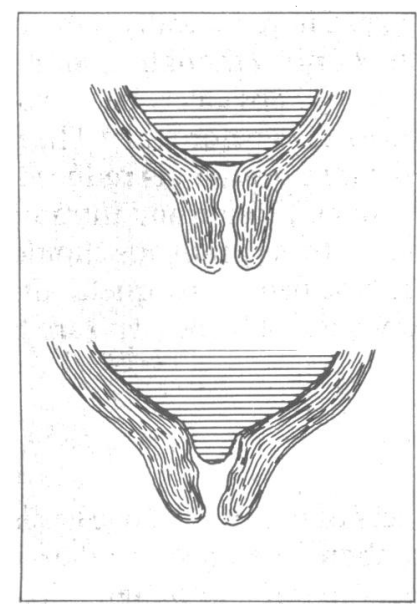

Cervical incompetence leads to a cone of unsupported membranes.
Reproductive history - A multiparous woman's obstetric history may give prognostic clues; the chances of a preterm delivery are tripled after one previous preterm birth and increased sixfold after two. These are two simple sets of risks; other outcomes bring in differential variables. Past studies have been diminished by not including the woman's total obstetric history, which needs careful consideration in the case of each woman.

Medical history-Recurrent lower urinary tract infections are not usually associated with recurrent preterm labour, although pyelonephritis may be. The renal tract should be investigated between pregnancies and reinfection prevented by prophylactic antibiotics in future pregnancies.
Effectiveness of cervical cerclage in reducing preterm delivery and rates of stillbirth, miscarriage, and neonatal death ${ }^{7}$

\begin{tabular}{|c|c|c|c|c|c|c|c|c|c|}
\hline & \multicolumn{2}{|c|}{ No in group } & \multicolumn{7}{|c|}{ Odds ratio and $95 \%$ confidence interval } \\
\hline & Experimental & Control & 0.01 & 0.1 & 0.5 & 1 & 2 & 10 & 100 \\
\hline \multicolumn{10}{|l|}{ Delivered: } \\
\hline Before 33 weeks & $59 / 454$ & $82 / 451$ & & & $\longrightarrow-$ & & & & \\
\hline Before 37 weeks & $124 / 454$ & $146 / 451$ & & & $\longrightarrow$ & & & & \\
\hline $\begin{array}{l}\text { Stillbirth, miscarriage, or } \\
\text { neonatal death }\end{array}$ & $37 / 454$ & $54 / 451$ & & & & - & & & \\
\hline
\end{tabular}

Data analysed to 1988
Uterine structural abnormalities can be a recurrent factor, the best documented being cervical incompetence, a mechanical diagnosis first observed by obstetricians in the 1940s and made familiar by the work of Shirodkar and McDonald in the 1950s. The truer picture of the place of cervical incompetence and its management in preterm labour had to await a randomised controlled trial in the late 1980s run jointly by the Medical Research Council and the Royal College of Obstetricians and Gynaecologists; the results put into proportion the importance of cervical incompetence as an individual factor in preterm delivery.

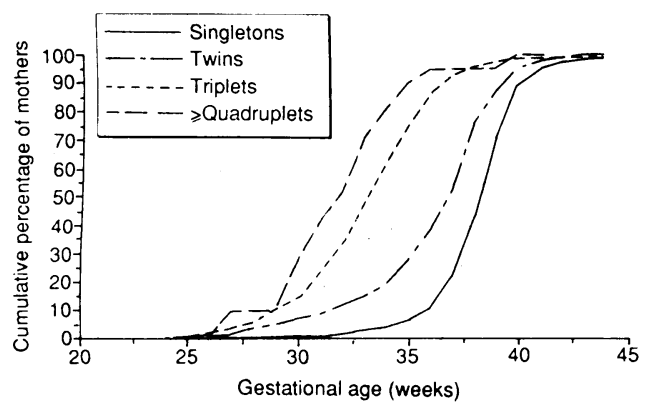

Cumulative gestational age at delivery for multiple pregnancies. By 37 weeks delivery has occurred in $97 \%$ of quadruplet, $96 \%$ of triplet, $55 \%$ of twin, and $25 \%$ of singleton pregnancies.

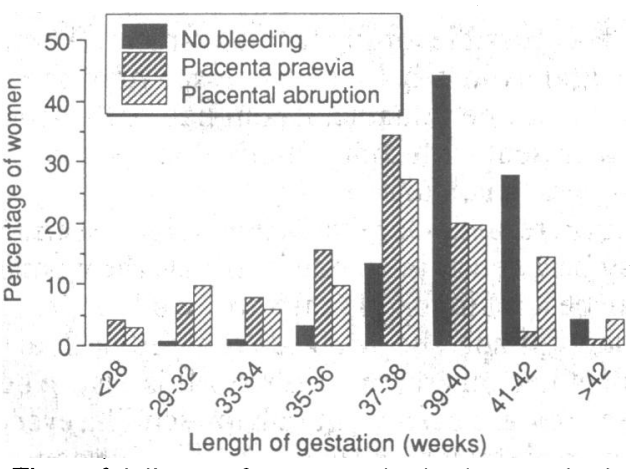

Time of delivery of women who had no vaginal bleeding in pregnancy compared with that in those with placenta praevia or placental abruption $(n=17005)$.
Complications of pregnancy-A twin pregnancy is a marker of a preterm labour. The mean gestation length of twins is 37 weeks and therefore a large number will be born before this time. Several National Birthday Trust studies have shown the importance in preterm labour of antepartum haemorrhage, irrespective of the cause of the bleeding.

An obvious but unusual factor associated with preterm labour is abdominal surgical intervention when appendicitis or complication of an ovarian cyst may require surgical treatment. The woman may go into labour after operation, but with modern relaxant anaesthesia most do not. Hard physical work in pregnancy is associated with preterm labour, particularly if it is repetitive and boring or in an unpleasant, noisy environment. This factor is discussed in the article on work in pregnancy.

Abnormalities of the fetus are often associated with polyhydramnios, which can lead to premature membrane rupture and preterm labour.

Infection and premature membrane rupture - Infection of the lower uterus and the membranes is an important feature that is poorly investigated epidemiologically. The presence of micro-organisms in the membranes is associated with an increased production of prostaglandins, one of the main factors associated with the onset of labour. Proteases, coagulases, and elastases are also produced by invading micro-organisms, whose endotoxins may stimulate labour directly as well as through prostaglandin metabolism. Low grade infection of the uterus and its linings is much commoner after premature rupture of the membranes, when an ascending infection of the vagina may produce such biochemical changes. One of the commonest organisms is the $\beta$ haemolytic streptococcus, which is found as a commensal in the vagina in about $5 \%$ of women but may be the cause of preterm labour in up to $20 \%$. Premature membrane rupture itself is a commonly quoted cause of preterm labour, but just as important may be the effect of infection weakening the forewaters or the removal of their mechanical support from the cervix. 
Major indications for induction of preterm labour

- Pregnancy induced proteinuric hypertension

- Intrauterine growth retardation
Induction-Preterm labour is also caused iatrogenically: labour is induced in about $15 \%$ of women in this country, though in some units the rate rises to $40 \%$. Many of the inductions will obviously be in women after 37 weeks' gestation but some will be performed before this. The problem of rhesus incompatibility, previously a major indication, is reduced; in its place is pregnancy induced proteinuric hypertension and intrauterine growth retardation. Women with either of these problems should be delivered at hospitals that can cope with the neonatal sequelae of such inductions, which produce a large proportion of babies who are born well before the 37 th week of pregnancy.

\section{Prevention}

The recognition of some of the triggers of preterm labour has led a few obstetricians to take action to prevent labour. Bed rest and the use of prophylactic tocolytic agents are not very helpful, although a doctor might use either of these managements to satisfy a mother who has previously undergone preterm labour and has faith in them. Repeated, carefully taken, high vaginal swabs to give the pattern of micro-organisms in the upper vagina may be useful. Should the organisms found be relevant - for example, $\beta$ haemolytic streptococcus or listeria - active antibiotic treatment may eradicate colonisation and thus reduce the risks of preterm labour. This approach is under evaluation.

Several centres have used programmes during early and mid-pregnancy to educate women with a history of preterm delivery to try to prevent a recurrence of the problem. There is no easy method of doing this in a group; the success of such programmes depends on the individual woman and her individual attendants. All the factors discussed must be considered, and the woman should obviously try to avoid those which seem to be the more active in her case. Even with the most intensive antenatal education programmes, preterm deliveries are not cut to less than about $3 \cdot 5 \%$, a background rate in many populations. Success in this subject may come eventually after a conscious effort to modify the lifestyle, socioeconomic conditions, and medical problems of each individual patient.
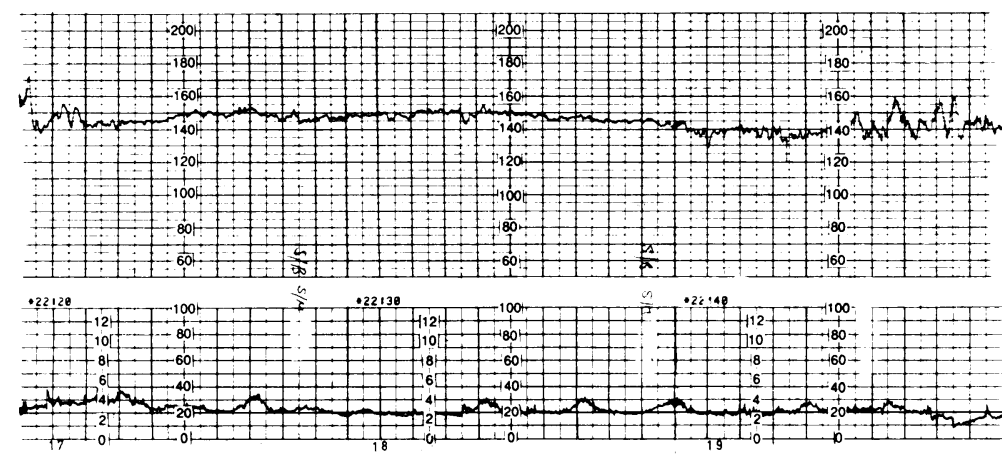

Tocogram with fetal heart rate above and uterine pressure below. Regular small contractions of the uterus are seen.
Diagnosis-As with labour at term, diagnosing the onset of preterm labour is much easier retrospectively than at the time. You can look back and say a labour probably started at a certain time, but to do so prospectively is much harder. The general practitioner is left with the difficult task of deciding whether any group of uterine contractions will progress to cervical dilatation or whether they are just stronger Braxton Hicks contractions. The diagnosis is probably best assisted by tocographic measurement of uterine contractions with a semiquantitative external monitor. Any woman thought to be in preterm labour should go to the local maternity unit as soon as possible for further assessment. There tocography may help, and assessment of the cervix may be valuable. About half of the women who present with contractions alone will not progress to labour.

If preterm labour seems inevitable, treatment may be given to postpone it. If not, the woman may be kept in for 24 hours to see if labour follows; if not, she can be discharged back to the care of her general practitioner. It is easy to be wise after the event, but only by sending every woman about whom there is reasonable doubt to the maternity unit will clinicians not miss the occasional woman who goes into very early preterm labour. 


\section{Inhibition of established preterm labour}

Before 32 weeks' gestation short term inhibition of labour allows:

- Transfer to best equipped delivery unit

- Steroids to be given to help mature the fetal respiratory system
If a woman is in real preterm labour a decision has to be made whether labour should be stopped. It is probably wise not to do so when the mother's blood pressure is greatly raised, there is proved infection in the endocervical or decidual regions, or the fetus has a lethal abnormality. Some obstetricians would further consider that it was unwise to inhibit labour in the presence of long term rupture of the membranes, severe intrauterine growth retardation, or an antepartum haemorrhage. Each of these cases must be decided on their own merits.
Effectiveness of $\beta$ mimetic tocolytics used in preterm labour in reducing perinatal death. The numbers are the proportions of perinatal deaths

\begin{tabular}{|c|c|c|c|c|c|c|c|c|c|}
\hline \multirow[b]{2}{*}{ Study } & \multicolumn{2}{|c|}{ No in group } & \multicolumn{7}{|c|}{ Odds ratio and $95 \%$ confidence interval } \\
\hline & Experimental & Control & 0.01 & 0.1 & 0.5 & 1 & 2 & 10 & 100 \\
\hline Christensen et al(1980) & $1 / 14$ & $0 / 16$ & & & & & & & \\
\hline Spellacy et al (1979) & $1 / 15$ & $4 / 15$ & & & & & - & & \\
\hline Barden (unpublished) & $1 / 12$ & $0 / 13$ & & & & & & & \\
\hline Hobel (unpublished) & $2 / 17$ & $0 / 16$ & & & & & & & \\
\hline Cotton et al (1984) & $1 / 19$ & $4 / 19$ & & & & & & & \\
\hline Howard et al (1982) & $1 / 16$ & $1 / 21$ & & & & & & & \\
\hline Ingemarsson (1976) & $0 / 15$ & $0 / 15$ & & & & & & & \\
\hline Larsen et al (1986) & $1 / 49$ & $2 / 50$ & & & & & & & \\
\hline Calder and Patel (1985) & $0 / 37$ & $1 / 39$ & & & — & & & & \\
\hline Scommegna (unpublished) & $0 / 16$ & $1 / 17$ & & & — & & & & \\
\hline Mariona (unpublished) & $1 / 4$ & $1 / 5$ & & & & & & & \\
\hline Wesselius-De Casparis et al & $2 / 33$ & $1 / 30$ & & & & & & & \\
\hline Leveno et al(1986) & $2 / 56$ & $3 / 55$ & & & & & $\bullet$ & & \\
\hline Larsen et al (1980) & $11 / 131$ & $2 / 45$ & & & & & & & \\
\hline Adam (1966) & $9 / 28$ & $7 / 24$ & & & & & & & \\
\hline $\begin{array}{l}\text { Typical odds ratio and } \\
95 \% \text { confidence interval }\end{array}$ & & & & & & & & & \\
\hline
\end{tabular}

Effectiveness of $\beta$ mimetic tocolytics used in preterm labour in reducing preterm delivery. The numbers are the proportions of women delivering before 37 weeks

\begin{tabular}{|c|c|c|c|c|c|c|c|c|c|}
\hline \multirow[b]{2}{*}{ Study } & \multicolumn{2}{|c|}{ No in group } & \multicolumn{7}{|c|}{ Odds ratio and $95 \%$ confidence interval } \\
\hline & Experimental & Control & 0.01 & $0 \cdot 1$ & 0.5 & 1 & 2 & 10 & 100 \\
\hline Christensen et al (1980) & $14 / 14$ & $16 / 16$ & & & & & & & \\
\hline Spellacy et al (1979) & $12 / 14$ & $13 / 15$ & & & & & & & \\
\hline Barden (unpublished) & $6 / 12$ & $13 / 13$ & & & & & & & \\
\hline Hobel (unpublished) & $10 / 16$ & $8 / 15$ & & & & & & & \\
\hline Cotton et al (1984) & $15 / 19$ & $16 / 19$ & & & & & & & \\
\hline Howard et al (1982) & $9 / 15$ & $5 / 18$ & & & & & & & \\
\hline Ingemarsson (1976) & $3 / 15$ & $12 / 15$ & & & 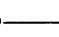 & & & & \\
\hline Larsen et al (1986) & $14 / 49$ & $23 / 50$ & & & - & & & & \\
\hline Calder and Patel (1985) & $23 / 37$ & $19 / 39$ & & & & & & & \\
\hline Scommegna (unpublished) & $10 / 15$ & $10 / 16$ & & & & & & & \\
\hline Mariona (unpublished) & $3 / 4$ & $3 / 5$ & & & - & & $\bullet$ & & \\
\hline \multicolumn{10}{|l|}{ Wesselius-De Casparis et al } \\
\hline (1971) & $13 / 33$ & $21 / 30$ & & & & & & & \\
\hline Leveno et al (1986) & $40 / 54$ & $42 / 52$ & & & & & & & \\
\hline Larsen et al (1980) & $65 / 131$ & $21 / 45$ & & & & & 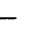 & & \\
\hline Sivasamboo (1972) & $14 / 33$ & $20 / 32$ & & & & & 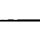 & & \\
\hline $\begin{array}{l}\text { Typical odds ratio and } \\
95 \% \text { confidence interval }\end{array}$ & & & & & & & & & \\
\hline
\end{tabular}

Note the small numbers and wide confidence intervals in some of the studies in these two meta-analyses
Other than these exceptions, in most cases before 28 weeks it is worth trying to stop preterm labour to buy intrauterine time for the fetus. In the short term this can allow emergency treatment such as steroids to help maturation of the fetal respiratory system or allow transfer of the woman to a centre where better neonatal care can look after a small baby when he or she is born. These decisions must be made in consultation with the paediatricians as the practical management of any baby that may result from a preterm labour will depend on their skills and facilities. In a large well equipped obstetricpaediatric unit the borderline comes at about 32 weeks, provided that all other features of the pregnancy are normal.

If it is considered necessary to stop preterm labour a range of agents exist. Alcohol and progestogens are obsolete. Prostaglandin synthesis inhibitors (such as indomethacin) are effective but have strong side effects in mother and fetus. Calcium antagonists are currently undergoing trial. The main agents in current use are $\beta$ agonists, of which the commonest two in the United Kingdom are ritodrine and salbutamol. These drugs work equally well on the myometrial cells, postponing labour for a short time. There is little evidence from meta-analyses of many studies that they reduce either perinatal mortality rates or postponement of labour over a longer period. Their use will depend on the ripeness of the cervix - the less ripe the more likely that action will be effective. They are best used before 32 weeks of pregnancy and probably work better in the absence of infection. Though little evidence shows that prophylactic oral $\beta$ mimetic agents prevent preterm labour, oral maintenance after intravenous inhibition has some use.

Ritodrine and salbutamol have side effects, the most noticeable being tachycardia felt as palpitations in the neck; they may also be associated with mild sweating and headache. Rare cases of pulmonary oedema have been reported, and it is essential to watch the woman's fluid intake, particularly if the tocolytic agent is being given intravenously. Some have reported fetal macrosomia after long term use of $\beta$ agonists, but this is unusual. They are better not used or used only with extreme caution in women with cardiac disease, hyperthyroidism, or diabetes. 


\section{Expert care for babies expected to be very small}

- In utero transfer to obstetric/neonatal referral centre

- Delivery in district general hospital and ex utero transfer to specialist centre
Once treatment with $\beta$ agonists has been started, the next decision is where the woman is to deliver if labour proceeds. If the unit cannot cope with very small babies in utero transfer must be considered. The woman should be sent to a tertiary referral centre in the region that can manage babies of this degree of immaturity. The alternative philosophy is to allow the baby to be delivered in the peripheral centre and, if necessary, transfer the child to the tertiary referral unit by ex utero transfer. There is much debate in the United Kingdom currently about which of these is more effective. In utero transfer may not seem to be necessary every time; it is used as a precaution and allows the woman to be in the tertiary referral centre that is able to provide more sophisticated obstetric as well as neonatal care-for example, Doppler flow studies. Ex utero transfer allows the woman to stay closer to her home at the local hospital she has chosen. However, specialist obstetric tests may not be available, expert paediatricians may not be available at the time of delivery because of the many other calls on their time, and road traffic conditions in United Kingdom are far from perfect to guarantee reaching the nearest specialist centre quickly. At present the philosophy has moved towards in utero transfer, but it may not stay so for long.

\section{Conclusions}

Preterm labour and small for gestational age fetuses constitute the most serious current problems in obstetrics
This article and last week's are concerned with the most serious problems of current obstetrics. Getting the best results for very small babies is the most hopeful line of advance for the 1990s. It needs coordination from family doctors, obstetricians, and neonatal paediatricians with individual treatments tailored to individual mothers.

$1 \mathrm{MRC} / \mathrm{RCOG}$ Working Party on Cervical Cerclage. Interim report of the Medical Research Council/Royal College of
Obstetricians and Gynaecologists multicentre randomised trial of cervical cerclage. Br f Obstet Gynaecol 1988;95:437-45.

The data for perinatal and neonatal mortality rates for Scotland are taken from the Scottish stillbirths and neonatal deaths report of 1989 produced by the Information Office of the Scottish Health Service. The figure showing the cumulative distribution of singleton and multiple births is reproduced by permission of the Office of Population Censuses and Surveys from Three, Four and More published by HMSO. The meta-analyses are based on those in Effective Care in Pregnancy and Childbirth edited by I Chalmers, M Enkin, and M J N C Keirse and published by Oxford University Press.

Professor Geoffrey Chamberlain, FRCOG, is chairman of the department of obstetrics and gynaecology, St George's Hospital Medical School, London.

\section{MIRROR OF MEDICINE}

Ill health prompted many of Hart's frequent visits abroad in the $1880 \mathrm{~s}$ and $1890 \mathrm{~s}$, for he found nothing so beneficial as a sea journey. Germany, France, Egypt, Gibraltar, Tangiers, Corfu, Madeira, the Canary Islands, India, Burma, the United States, Canada, and the West Indies were all visited in these years, and not merely for holidays. In 1893 he attended and addressed the American Medical Association's conference in Milwaukee. During his North African vacation in the following spring he wrote a series of articles on Tangiers as a health resort, while, on his return journey, he stopped off in Gibraltar, to assist in the formation of a BMA branch, and Paris, where he spoke on cholera. The following year saw him lecturing on public health in the Indian subcontinent. Even during his 1897 visit to the West Indies, in the course of which he was seriously ill, he attended a host of official functions and produced a series of articles for the fournal on the value of the islands as a health resort. Hart's ceaseless activity cannot have improved his health. In India, in 1895, dysentery brought him close to death; during his visit to the West Indies he was a virtual invalid. It may be that Hart's deteriorating health contributed to errors of judgment, for example, over publication of the "script," and added to the irascibility of an already "difficult" personality.

In the early 1890s Hart performed much of his editorial work at his Wimpole Street home. In 1896 he sold the London house and much of his Japanese art collection, resolving to live and work entirely in Hertfordshire.
During the summer of 1897 he performed most of his editorial work recumbent in his Totteridge garden. His clerk travelled out from London daily to assist him, though until September 1897 Hart continued to meet the Reference Committee once a week in London. It should not be assumed that Hart mellowed and entered into semiretirement some years before his death. He remained a forceful character who continued to court controversy throughout his last years. Legal actions and the threat of such actions had regularly punctuated Hart's editorship, and continued to occur in the 1890 s. Until close to the end he remained very much in charge of the fournal. Neither did the fournal's vitality fail as the editor's infirmity increased. Hart was mentally alert till the day he died. Some of the best sociomedical exposées - for example, of massage parlours, opiate abuse, the "new mesmerism," conditions in Irish workhouses and infirmaries, and the "barrack life of pauper children"-were published in the mid 1890 s. At the same time, the fournal published brilliant work on the newly discovered $x$ ray.

From Mirror of Medicine: A History of the BMf by P W J Bartrip. Published jointly by the $B M \mathcal{F}$ and Oxford University Press; BMA members' price UK f29 overseas $£ 33$, including postage. Obtainable from the Publishing Manager, $B M \mathcal{A}$, PO Box 295, London WC1H 9TE. Non-members UK £35. Obtainable from OUP Distribution Services, Saxon Way West, Corby, Northamptonshire NN18 9ES. 